\title{
SISTEM INFORMASI PENJUALAN DAN PEMESANAN LAYANAN BERBASIS WEB DAN SMS GATEWAY DI PETSHOP "PETZONE"
}

\author{
Siska Fadilah ${ }^{1)}$, Adian Fatchur Rochim ${ }^{2)}$, RintaKridalukmana ${ }^{2)}$ \\ Program Studi Sistem Komputer, Fakultas Teknik, Universitas Diponegoro \\ Jln. Prof. Sudharto, Tembalang, Semarang, Indonesia \\ Email: siskafadilah@gmail.com
}

\begin{abstract}
Abstrak-Dewasa ini teknologi informasi sangat membantu dalam dunia bisnis. Kemudahan yang ditawarkan akan menjaring lebih banyak konsumen. Namun, perusahan tingkat menengah seperti PetZone saat ini masih jarang yang menawarkan kemudahan berbelanja atau pemesanan layanan secara online. Oleh karena itu diperlukan sebuah sistem berbasis web di perusahaan PetZone yang dapat memudahkan pemilik dan karyawan dalam penjualan, pelayanan, dan pemasaran, serta memudahkan pelanggan dalam jual-beli barang dan jasa. Atas dasar masalah tersebut dibangun Sistem Informasi Penjualan dan Pemesanan Layanan Berbasis Web dan SMS Gateway untuk menunjang proses bisnis yang ada.

Sistem informasi dibangun menggunakan bahasa pemrograman PHP framework Codeigniter, javascript untuk tampilan yang dinamis, dan database MySQL. Proses pembuatan dan pengembangan Sistem Informasi Penjualan ini menggunakan metode air terjun. Metode air terjun meliputi kebutuhan pengguna, analisis, rancangan, implementasi dan pengujian. Pemodelan Sistem Informasi yang dibangun menggunakan metode berorientasi objek UML (Unified Modeling Language) yang terdiri dari Use case diagram, Class diagram dan Sequence diagram.

Hasil pengujian Sistem Informasi Penjualan dan Pemesanan Layanan Berbasis Web dan SMS Gateway menunjukkan bahwa semua fitur yang terdapat baik dalam sistem informasi maupun SMS gateway dapat bekerja dengan baikdengan ratusan sample data, dan server SMS gateway dapat memproses lebih dari satu SMS secara bersamaan. Dalam perkembangan ke depannya nanti, Sistem Informasi Penjualan dan Pemesanan Layanan Berbasis Web dan SMS Gateway masih dapat dikembangkan lagi dengan menambah fitur-fitur pada SMS gateway sehingga lebih memudahkan konsumen.
\end{abstract}

Kata kunci : Sistem Informasi Berbasis Web, SMS gateway, PHP, Codeigniter, MySQL, Javascript, UML.

\section{PENDAHULUAN}

Perkembangan teknologi informasi yang sangat cepat telah menjadi pendukung utama untuk memperoleh informasi dengan cara mudah dan cepat. Hal tersebut menjadi perhatian bagi perusahaan kelas menengah seperti PetZone untuk meningkatkan pemasaran dan pelayanan, guna menarik pelanggan dan mengatasi persaingan antar perusahaan sejenis yang bergerak dalam bidang Pet Shop. Untuk mengatasi persaingan di dunia teknologi seperti sekarang ini diperlukan sebuah Sistem Informasi untuk meningkatkan penjualan, pelayanan dan pemasaran yang lebih luas oleh sebuah perusahaan.

Selain Sistem Informasi, media Short Message Service (SMS) akan memberikan Peningkatan pelayanan pemberian informasi sesuai kebutuhan dengan cepat dan akurat dimanapun pengguna informasi berada, itu yang menjadi keunggulan yang diberikan oleh SMS gateway ini. Sistem ini memiliki kemampuan menerima dan menyampaikan informasi lewat Short Message Service (SMS) dan mengelola informasi tersebut ke dalam bank data (database). Berdasarkan latar belakang masalah tersebut, dapat dibuat suatu rumusan masalah yaitu: "Bagaimana menciptakan sebuah Sistem Informasi Berbasis Web dan SMS Gateway di perusahaan PetZone, Semarang, yang dapat memudahkan pemilik dan karyawan dalam penjualan, pelayanan dan pemasaran, serta memudahkan pelanggan dalam jual-beli hewan peliharaan (Pet) di PetZone?". Sehingga, tujuan dalam tugas akhir ini adalah membangun sebuah sistem informasi yang dapat mempermudah layanan transaksi dan memperluas jangkauan penjualan dan pemasaran produk hingga mencakup pasar nasional dan mengimplementasikan bahasa pemrograman PHP untuk membangun sebuah sistem informasi berbasis web dan SMS gateway.

\section{DASAR TEORI}

\subsection{Pengertian Sistem Informasi}

Sistem adalah sekelompok bagian-bagian (alat dan sebagainya) yang bekerja bersama-sama untuk melakukan suatu maksud. Informasi adalah makna atau pengertian yang dapat diambil dari suatu data dengan mengunakan konversi-konversi yang umum digunakan di dalam representasinya. Suatu sistem adalah jaringan kerja dari prosedur-prosedur yang saling berhubungan, berkumpul bersama-sama untuk melakukan suatu kegiatan atau menyelesaikan suatu sasaran tertentu. Prosedur adalah suatu urutan-urutan operasi tulis-menulis dan biasanya melibatkan beberapa orang dalam satu atau lebih departemen ${ }^{[2]}$.

Informasi adalah kumpulan data yang diolah menjadi bentuk yang lebih berguna dan lebih berarti bagi yang menerima. Banyak atribut dalam konsep informasi yang membantu kita dalam mengidentifikasi dan mendeskripsikan kebutuhan-kebutuhan informasi yang spesifik $^{[2]}$.

\subsection{Pengertian Unified Modeling Language (UML)}

Unified modeling language (UML) adalah sebuah "bahasa" yang menjadi standar dalam industri untuk visualisasi, merancang dan mendokumentasikan sistem piranti lunak. UML menawarkan sebuah standar untuk merancang model sebuah sistem ${ }^{[5] \text {. }}$ 


\section{$2.3 \quad$ MySQL}

MySQL merupakan basis data yang menggunakan konsep RDBMS, sebuah tabel merupakan struktur penyimpanan dasar. Satu tabel atau lebih membentuk sebuah relational database [3].

MySQL adalah Relational Database Management System (RDBMS) yang didistribusikan secara gratis di bawah lisensi GPL (General Public Licence). Dimana setiap orang bebas untuk menggunakan MySQL, namun tidak boleh dijadikan produk turunan yang bersifat closed source atau komersial[3].

\subsection{Codeigniter}

Codeigniter adalah sebuah web application framework yang bersifat open source digunakan untuk membangun aplikasi php dinamis. Tujuan utama pengembangan Codeigniter adalah untuk membantu developer untuk mengerjakan aplikasi lebih cepat daripada menulis semua code dari awal. Codeigniter menyediakan berbagai macam library yang dapat mempermudah dalam pengembangan.Codeigniter diperkenalkan kepada publik pada tanggal 28 februari 2008[8].

\subsection{SMS Gateway}

Pada prinsipnya, SMS Gateway adalah sebuah perangkat lunak yang menggunakan bantuan komputer dan memanfaatkan teknologi seluler yang diintegrasikan guna mendistribusikan pesan-pesan yang di-generate lewat sistem informasi melalui media SMS yang dihandle oleh jaringan seluler [1].

Fitur-fitur standar SMS Gateway, yaitu komunikasi SMS interaktif dua arah, SMS info on demand, SMS service settings, SMS Automatic Registration, polling SMS, pengiriman SMS Broadcast, pengiriman SMS ke Call Group, pengiriman SMS terjadwal, personalisasi SMS, antarmuka aplikasi berbasis web, buku alamat dan call group, manajemen pengguna, sistem security acces, serta sistem parameter.

2.6 Gammu

Gammu adalah library dan utilitas command line untuk ponsel. Gammu dirilis di bawah GNU GPL versi 2.Diprakarsai oleh Marcin Wiacek dkk. Awalnya kode didasarkan pada Gnokii dan kemudian MyGnokii proyek. Gammu dulunya (sampai versi 0.58) disebut MyGnokii2. Saat proyek ini dipimpin oleh Michal Cihar dengan bantuan banyak kontributor.[4]

\section{ANALASIS DAN PERANCANGAN SISTEM}

\subsection{Tahap perancangan sistem}

Sistem informasi yang baik tidak lepas dari sebuah perancangan yang matang, Layaknya membuat sebuah bangunan tentulah dibutuhkan sebuah blueprint agar bangunan yang akan dibuat nantinya dapat tepat sasaran dan tepat guna. Oleh karena itu dalam perancangan aplikasi pada tugas akhir ini penulis menggunakan metode Waterfall. Metode Waterfall terdiri dari Requirements, Analysis, Design, Implementation, Testing. 3.2 Analisis Kebutuhan

Setelah melakukan wawancara dan pengamatan secara langsung dengan pihak terkait terhadap keadaan di
PetZone, proses kerja dibagi menjadi beberapa tahapan yang tertuang dalam tabel berikut:

Tabel 1 Kesimpulan proses bisnis

\begin{tabular}{|c|c|c|}
\hline Proses & Informasi & Kendala \\
\hline $\begin{array}{l}\text { 1. Penjualan } \\
\text { retail } \\
\text { accessories } \\
\text { dan pet food. }\end{array}$ & $\begin{array}{l}\text { - Harga barang } \\
\text { - Kuantitas } \\
\text { - Harga total }\end{array}$ & $\begin{array}{l}\text { - Proses penjualan } \\
\text { masih manual }\end{array}$ \\
\hline $\begin{array}{l}\text { 2. Pemesanan } \\
\text { pet hotel }\end{array}$ & $\begin{array}{l}\text { - Tanggal } \\
\text { booking } \\
\text { - Jenis hewan } \\
\text {-Data hewan } \\
\text {-Data pemiliki }\end{array}$ & $\begin{array}{l}\text { - Proses pencatatan } \\
\text { masih manual dan } \\
\text { efesiensi waktu } \\
\text { kurang } \\
\text {-Masih sering } \\
\text { terjadi kesalahan } \\
\text { dalam pencatatan } \\
\text {-Belum ada } \\
\text { pembukuan yang } \\
\text { rapi }\end{array}$ \\
\hline $\begin{array}{l}\text { 3. Jual Beli } \\
\text { Hewan }\end{array}$ & $\begin{array}{l}\text {-Data hewan } \\
\text {-Data pemilik }\end{array}$ & $\begin{array}{l}\text { - Proses pencatatan } \\
\text { masih manual dan } \\
\text { efesiensi waktu } \\
\text { kurang } \\
\text {-Hewan tidak } \\
\text { selalu tersedia di } \\
\text { toko. }\end{array}$ \\
\hline
\end{tabular}

Setelah mendeskripsikan proses bisnis dan disertai dengan informasi dan kendala yang ada, pihak pengguna (PetZone) menginginkan beberapa kondisi pada sistem informasi berdasar pada kendala yang dialami. Kebutuhan tersebut adalah manajemen penjualan online dan pemesanan pet hotel online. Fungsi utama perangkat lunak yang dibangun dibagi menjadi beberapa fasilitas untuk setiap aktor yang meliputi menu-menu apa saja yang ada pada aplikasi yang dibagun.

1 Fasilitas yang disediakan untuk aktor konsumen (user).

a. Setiap konsumen (user) dapat melihat katalog produk sesuai kategori dalam web, baik non member (konsumen yang belum login) maupun member (konsumen yang sudah login)

b. Non member dapat melakukan registrasi agar dapat melakukan pembelian secara online.

c. Member dapat mengedit akun yang berisi password dan username.

d. Member dapat mengisi profil user yang berisi identitas untuk melakukan pengiriman barang.

e. Member dapat melakukan pembelian secara online.

f. Member dapat meng-upload hewan yang akan dijual.

g. Member dapat melakukan pemesanan jadwal penjemputan menggunakan SMS gateway.

2. Fasilitas yang disediakan untuk aktor Admin

a. Setiap admin dapat mengelola data konsumen dan data admin dimana admin bisa menambah, mengubah dan menghapus data user (admin dan konsumen).

b. Admin dapat mengolah data master yaitu data produk (foto, deskripsi produk dan stok yang ada), kategor dan subkategori dimana data 
master tersebut dapat ditambah, diubah dan dihapus oleh admin.

c. Admin dapat mengelola data transaksi, memberi status pemesanan yang sudah diproses atau belum.

d. Admin dapat mengelola pengaturan website berupa judul, kata sambutan pada website dan menuliskan promosi apa saja yang sedang berjalan.

e. Admin dapat melihat laporan transaksi dari semua konsumen.

f. Admin dapat melakukan logout (keluar dari sistem)

\subsection{Analisa}

Untuk memahami sifat dan fungsi perang-kat lunak yang akan dibangun, analisa harus memahami domain informasi, dan tingkah laku yang diperlukan dan mengacu pada tahap sebelumnya yaitu analisis kebutuhan.

\subsubsection{Aktor yang terlibat}

Aplikasi Sistem Informasi yang dibangun akan digunakan oleh dua orang aktor yaitu admin da user (konsumen). Deskripsi dari masing-masing aktor adalah sebagai berikut :

Tabel 2 Deskripsi masing-masing aktor

\begin{tabular}{|c|c|c|}
\hline No & Aktor & Deskripsi \\
\hline 1 & Admin & $\begin{array}{l}\text { Admin memiliki hak akses } \\
\text { tertinggi untuk mengelola } \\
\text { data master yang ada dalam } \\
\text { database yaitu data admin } \\
\text { dan } \text { user, data produk } \\
\text { (kategori, sub kategori, foto } \\
\text { produk dan deskripsi } \\
\text { produk) dan melihat laporan } \\
\text { transaksi. }\end{array}$ \\
\hline 2 & User & $\begin{array}{l}\text { user bisa melihat produk } \\
\text { berdasarkan kategori, } \\
\text { melakukan registrasi, dan } \\
\text { melakukan login. Setelah } \\
\text { login } \text { user dapat melakukan } \\
\text { transaksi, mengedit profil } \\
\text { dan mengirim SMS. }\end{array}$ \\
\hline
\end{tabular}

\subsubsection{Kebutuhan fungsional}

Melihat dari tahapan dan disertai dengan keinginan pengguna dalam fitur yang ada dari aplikasi, fungsi yang muncul dikelompokkan menjadi dua meliputi:

1. Admin

Berisi fungsi untuk mengelola semua data master yang ada dalam sistem informasi.
a. Login
Untuk mengelola semua data master, admin terlebih dahulu melakukan login agar keamanan data terjaga.
b. Kategori
Berfungsi untuk mengelola kategori produk dan deskripsi kategori.
c. Produk

Berfungsi untuk mengelola produk, menambah, menghapus atau mengubah data produk yang berupa harga, stok, deskripsi produk dan gambar produk.

d. User

Berfungsi untuk mengelola user, menambah, menghapus atau mengubah data user.

e. Laporan penjualan

Berisis record informasi transaksi yang dilakukan oleh semua user, admin dapat menrubah status pemesanan apakah sudah diproses atau belum dan terdapat uga fungsi untuk mencetak laporan tersebut dalam bentuk PDF.

f. Jual beli

Berfungsi untuk mengelola data jual-beli yang dilakukan oleh user, admin dapat menghapus dan menrubah data namun tidak dapat menambah data.

g. Jadwal booking

Berfungsi untuk mengelola data pemesanan pet Hotel, menambah, menghapus, merubah data dan mencetaknya dalam penduk PDF.

h. Jadwal Jemput

Berfungsi untuk mengelola data jemput, menambah, menghapus, merubah data dan mencetaknya dalam penduk PDF.

i. Pengaturan

Berisi fungsi untuk mengatur tampilan web, judul utama dan kata sambutan di awal home website.

j. SMS Gateway

Berisi fungsi-fungsi SMS, seperti send SMS, outbox, inbox dan sent item. Selain itu juga terdapat fungsi autoreply untuk membalas SMS pemesanan dan konfirmasi pembaaran yang masuk dari user.

\section{Publik}

Halaman ini yang nantinya akan diakses oleh $u s e r$, yang berisi fungsi-fungsi sebagai berikut:

a. Registrasi

Agar dapat mendapatkan mengakses menu-menu di PetZone online, user terlebih dahulu harus melakukan registrasi.

\section{b. Login}

User yang sudah melakukan registrasi dapat melakukan login untuk mengakses menu-menu lain yang ada di PetZone online.

\section{c. Profil}

Menu profil ini berisi form data diri user yang nantinya akan digunakan dalam pengiriman barang, penjemputan atau digunakan untuk identitas di forum jual-beli online .

d. Edit

User juga dapat melaukan penggantian username dan password melalui menu Edit.

e. Record

Menu record menampil-kan riwayat belanja dari user, user dapat melihat status order nya apakah sudah diproses atau belum.

\section{f. Booking}

Menu booking berisi form booking untuk pet hotel. g. Forum jual-beli 
Dalam menu forum jual-beli user dapat melihat-lihat hewan yang ditawarkan oleh user lain, user juga dapat menambahkan hewan yang akan dijual atau ditawarkan ke user lain dengan mengisi form dan mengunggah foto hewan yang akan dijual.

\subsection{Design}

Tahap ketiga adalah tahap perancangan perangkat lunak yang merupakan proses multi langkah dan berfokus pada beberapa atribut perangkat lunak. Proses ini berdasarkan dari analisis sebelumnya sehingga menciptakan sebuah rancangan yang sesuai dengan kebutuhan dari pihak PetZone. Dalam perancangan ini, pengembang menggunakan metode Unified Modeling Language (UML).

\subsubsection{Diagram Use case}

Berikut adalah diagram use case dari sistem informasi penjualan dan pemesanan layanan di PetZone:

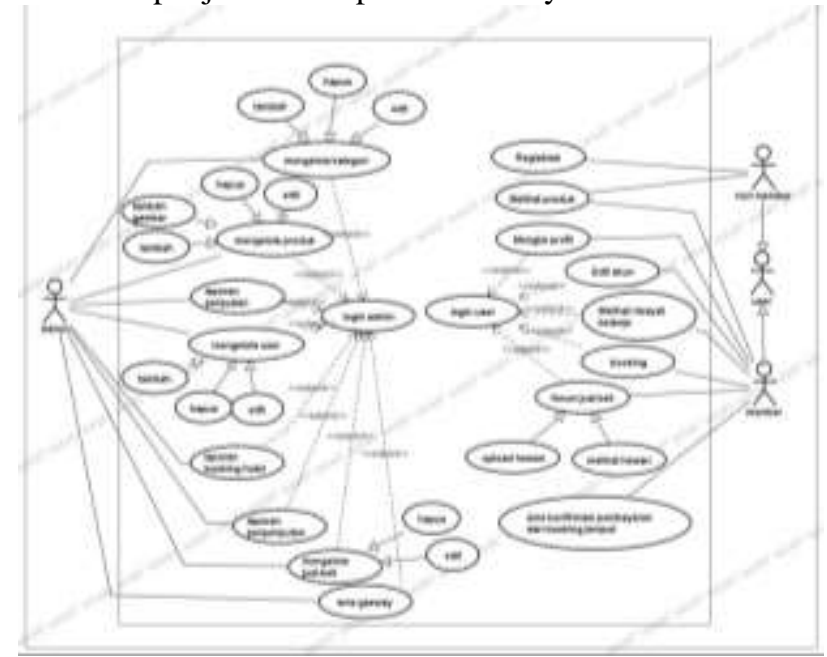

Gambar 1. Diagram Use case Sistem Yang Dibangun

3.4.2 Class diagram

Class diagram menggambarkan struktur dan deskripsi class, package, dan objek beserta hubungan satu sama lain seperti containment, pewarisan, asosiasi, dan lainain. Class diagram berfungsi untuk menjelaskan tipe dari objek sistem dan hubungannya dengan objek yang lain. Objek adalah nilai tertentu dari setiap attribute kelas entity. Berikut kelas diagram dari sistem yang akan dibangun ditunjukkan pada Gambar 3:

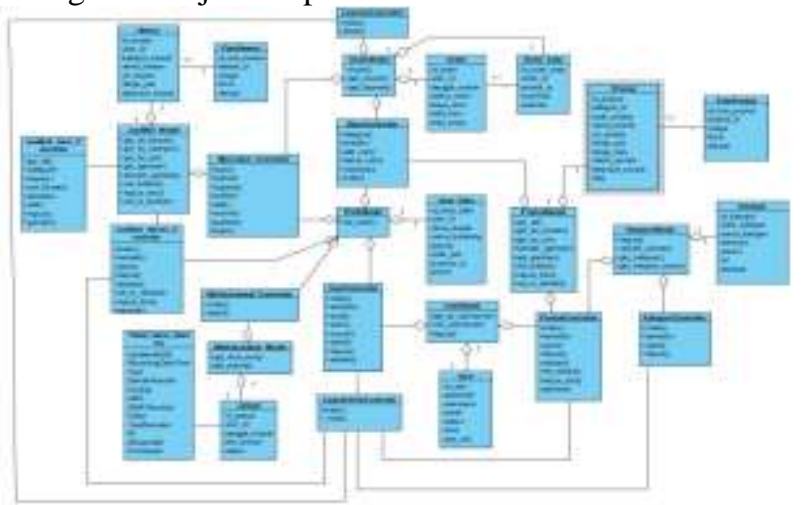

Gambar 2. Class diagram Sistem Yang Dibangun

\subsubsection{Sequence diagram}

1. Sequence diagram untuk Use case Login User Sequence diagram untuk Use case Help dapat dilihat pada Gambar 3.

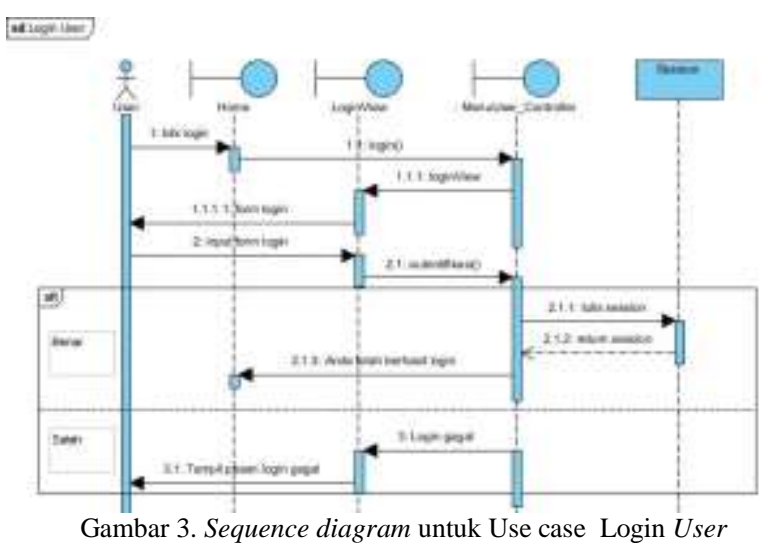

2. Sequence diagram untuk Use case Registrasi

Sequence diagram untuk Use case Registrasi dapat dilihat pada Gambar 4.

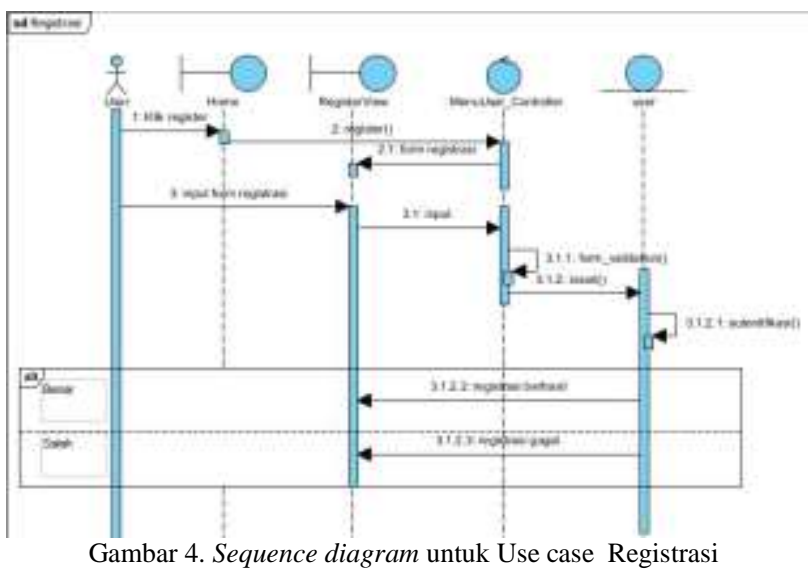

3. Sequence diagram untuk Use case Mengisi Profil Sequence diagram untuk Use case Mengisi Profil dapat dilihat pada Gambar 5.

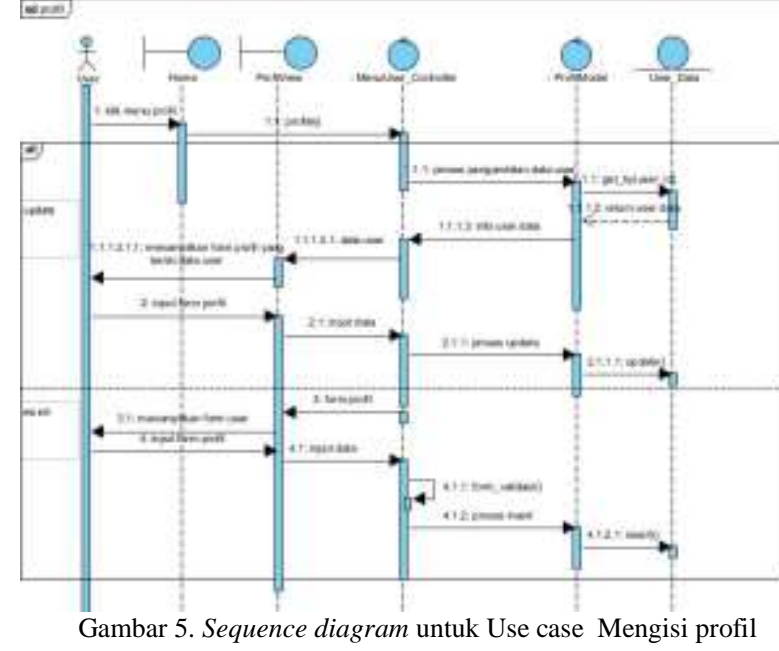

4. Sequence diagram untuk Use case Edit Akun Sequence diagram untuk Use case Edit Akun dapat dilihat pada Gambar 6. 


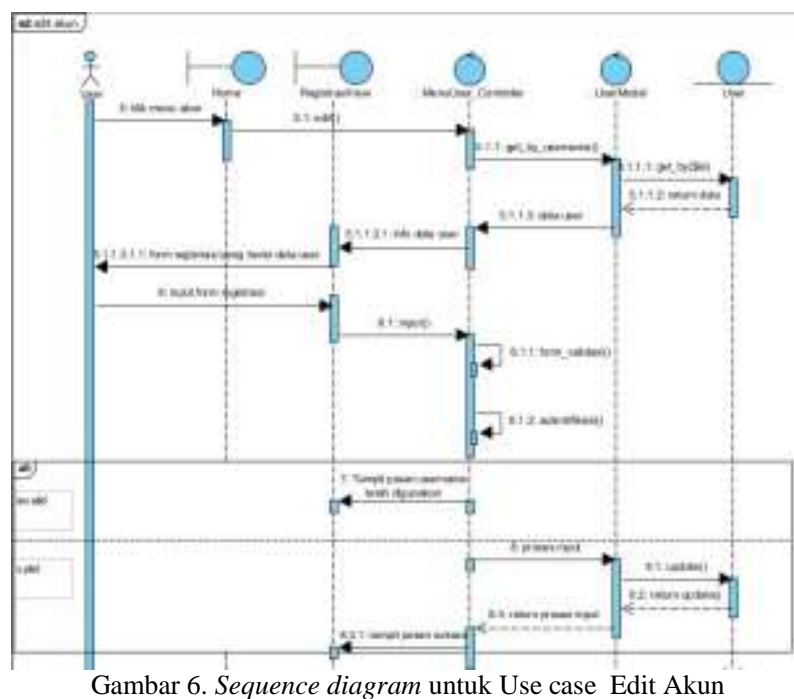

5. Sequence diagram untuk Use case Melihat Produk

Sequence diagram untuk Use case Melihat Produk dapat dilihat pada Gambar 7.

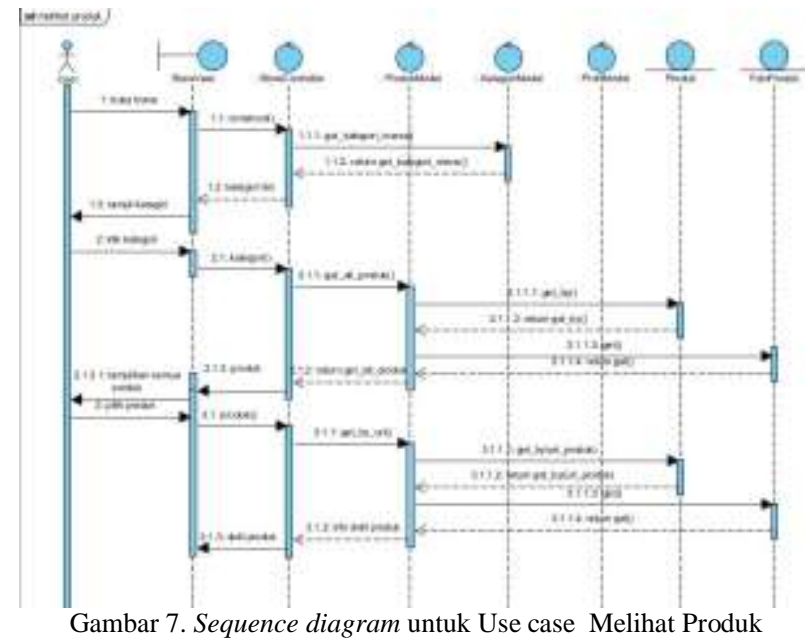

6. Sequence diagram untuk Use case Order Sequence diagram untuk Use case Order dapat dilihat pada Gambar 8.

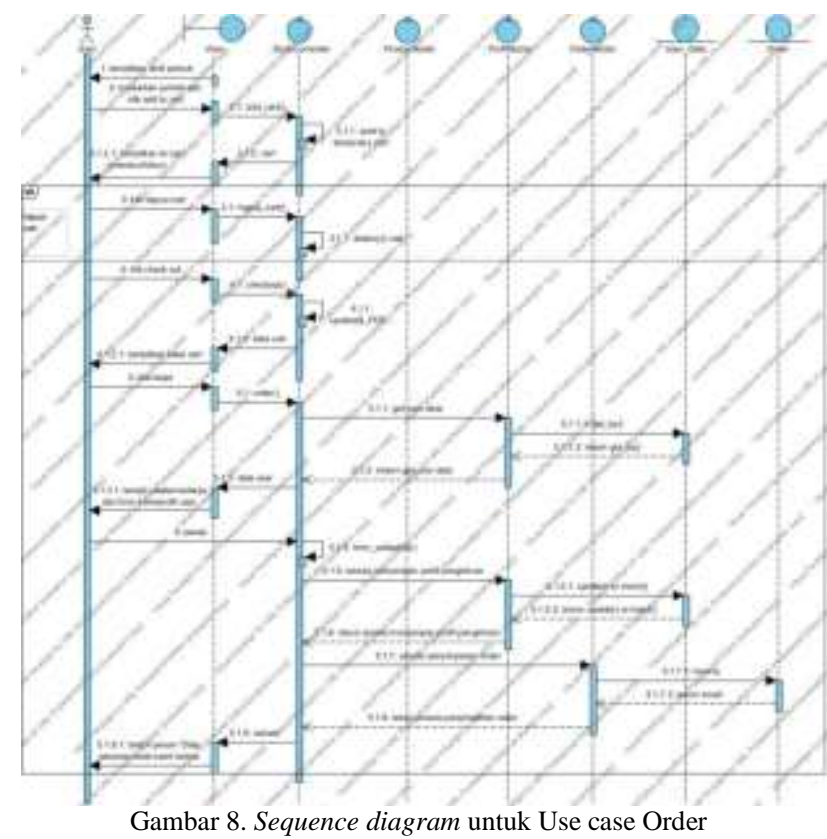

7. Sequence diagram untuk Use case Melihat Riwayat Belanja

Sequence diagram untuk Use case Melihat Riwayat Belanja dapat dilihat pada Gambar 9.

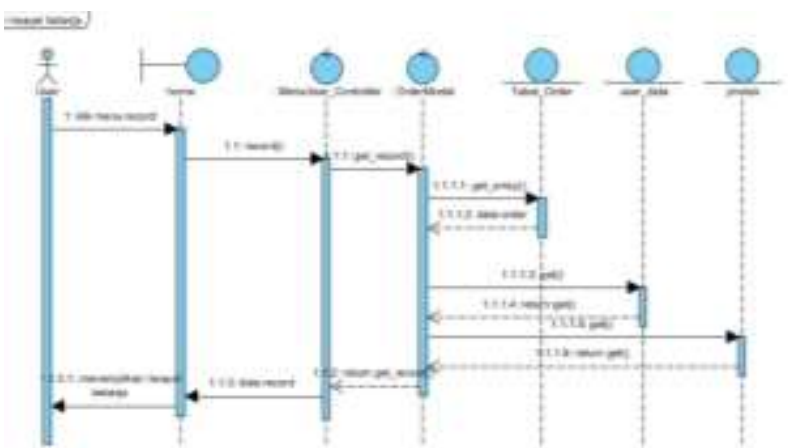

Gambar 9. Sequence diagram untuk Use case Melihat Riwayat Belanja

8. Sequence diagram untuk Use case Melihat Profil Hewan

Sequence diagram untuk Use case Melihat Profil Hewan dapat dilihat pada Gambar 10.

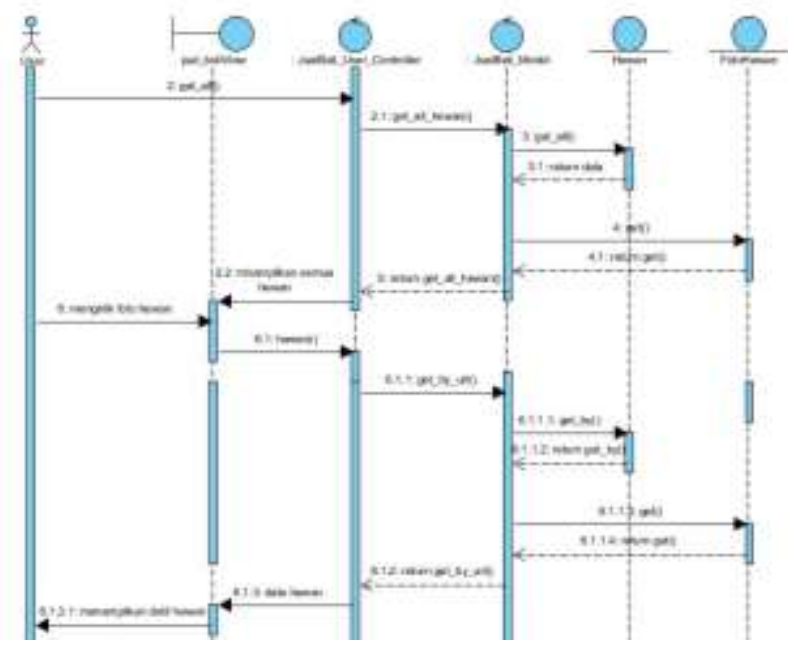


Gambar 10. Sequence diagram untuk Use case Melihat Profil Hewan

9. Sequence diagram untuk Use case Mengunggah Data Binatang

Sequence diagram untuk Use case Mengunggah

Data Binatang dapat dilihat pada Gambar 11.

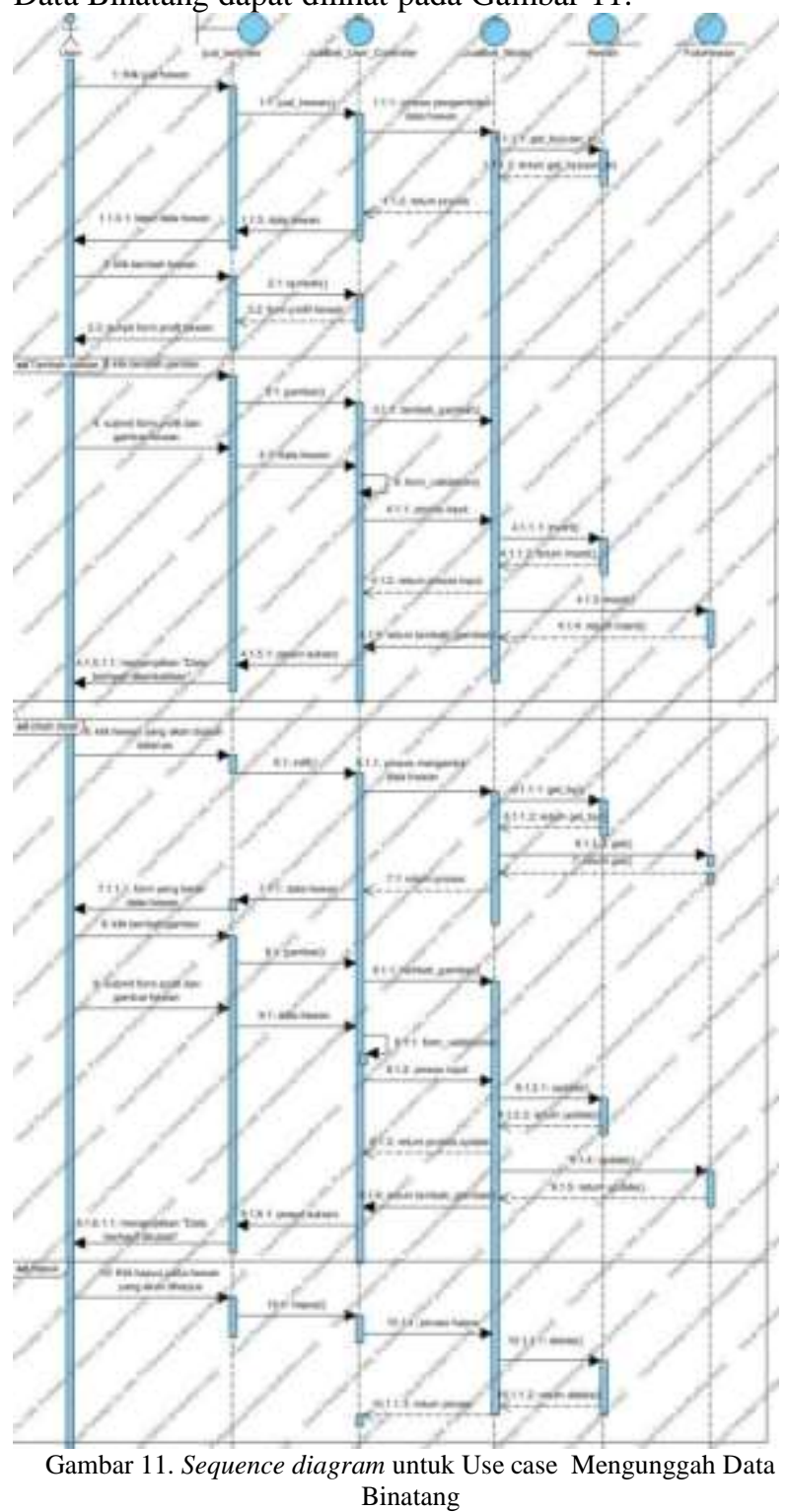

10. Sequence diagram untuk Use case Mengirim SMS Pemesanan layanan

Sequence diagram untuk Use case Mengirim SMS pemesanan Layanan dapat dilihat pada Gambar 12.

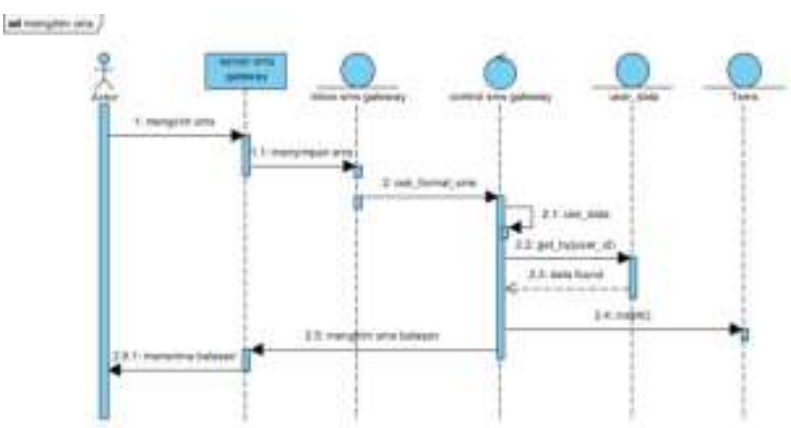

Gambar 12. Sequence diagram untuk Use case Mengirim SMS Pemesanan Layanan
11. Sequence diagram untuk Use case Mengelola Kategori

Sequence diagram untuk Use case Mengelola Kategori dapat dilihat pada Gambar 13.

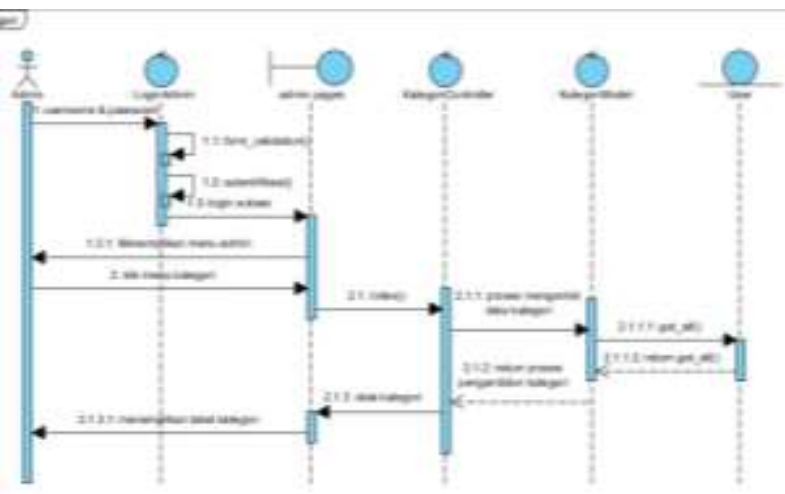

Gambar 13. Sequence diagram untuk Use case Mengelola Kategori 12. Sequence diagram untuk Use case Mengelola Produk

Sequence diagram untuk Use case Mengelola Produk dapat dilihat pada Gambar 14.

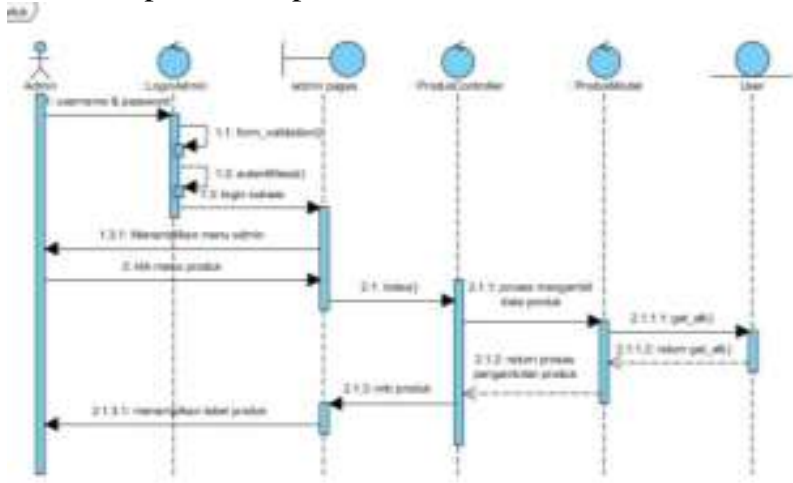

Gambar 14. Sequence diagram untuk Use case Mengelola Produk

13. Sequence diagram untuk Use case Mengelola User

Sequence diagram untuk Use case Mengelola User dapat dilihat pada Gambar 15.

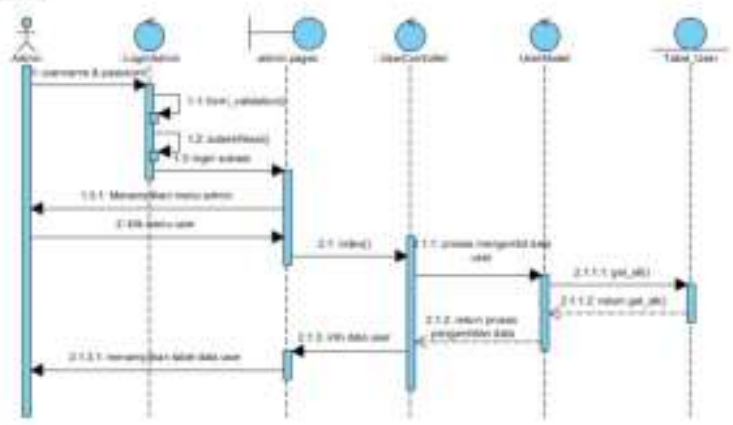

Gambar 5. Sequence diagram untuk Use case Mengelola User

14. Sequence diagram untuk Use case Melihat Laoran Penjualan

Sequence diagram untuk Use case Melihat Laporan Penjualan dapat dilihat pada Gambar 16. 


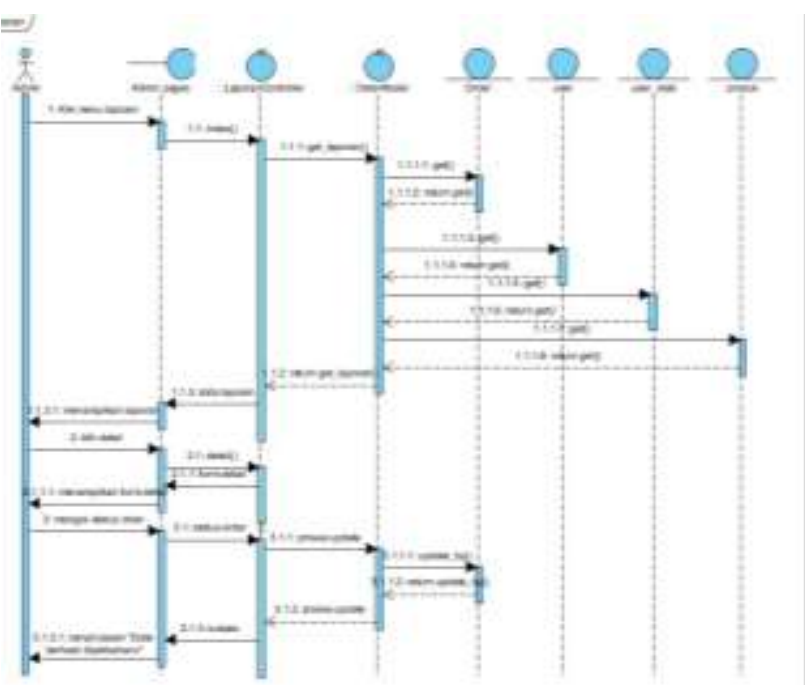

Gambar 16. Sequence diagram untuk Use case Melihat Laporan Penjualan

15. Sequence diagram untuk Use case Melihat Jadwal Penjemputan

Sequence diagram untuk Use case Melihat Jadwal Jemput dapat dilihat pada Gambar 17.

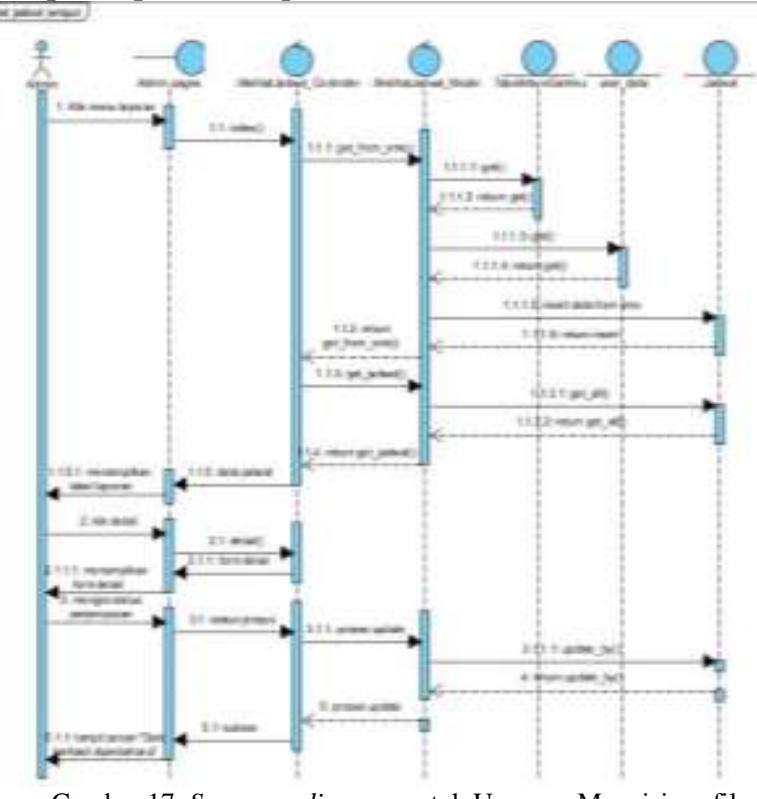

Gambar 17. Sequence diagram untuk Use case Mengisi profil

16. Sequence diagram untuk Use case Mengelola data Jual-Beli

Sequence diagram untuk Use case Mengelola Data Jual-Beli dapat dilihat pada Gambar 18.

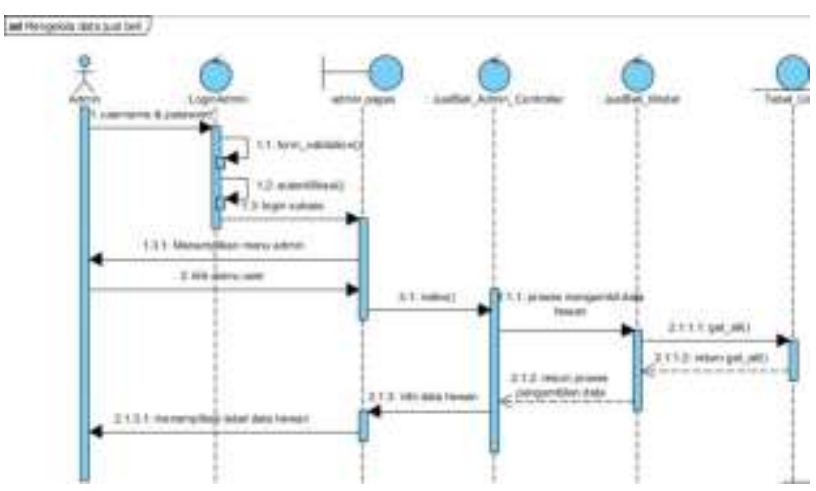

Gambar 18. Sequence diagram untuk Use case Mengelola Data Jual Beli

\section{IMPLEMENTASI}

Berdasarkan rancangan dan kebutuhan sistem, proses implementasi dibagi menjadi implementasi tabel dan implementasi program.Implementasi program yaitu mengimplementasikan rancangan tabel ke dalam database sesuai dengan analisis sebelumnya menggunakan MySQL dari XAMPP. Sedangkan implementasi program berisi potongan kode yang dibuat agar program berjalan sesuai dengan rancangan diagram alir dan User Interface yang memenuhi kebutuhan sistem.

4.1 Implementasi Tabel

Pembuatan Basis Data dilakukan menggunakan bahasa SQL(Structure Query Language ), dimana Basis Data ini atau DBMS (Database Management System) yang digunakan adalah MySQL.Adapun implementasi yang di bahas yaitu, tampilan Basis Data padaaplikasi server lokal Apache Xampp for Windows v.1.7.3.

\subsection{Implementasi Program}

Setelah database selesai dibentuk maka selanjutnya yaitu implementasi program. Pada implementasi program, dibagi menurut kategori dan fungsi sesuai rancangan sebelumnya. Dalam pengimplementasian desain user interface serta pengambilan data dalam database, digunakan module yang menampung variabel maupun method yang bersifat public sehingga dapat digunakan di seluruh class.

\subsection{Pengujian}

Proses pengujian menggunakan metode blackbox dibagi menurut fungsi dari masing-masing menu sesuai dengan kegunaannya. Bentuk pengujian berupa cara pengguna menggunakan aplikasi.

Tabel 3. Pengujian Sistem

\begin{tabular}{|c|c|c|c|}
\hline $\begin{array}{c}\text { Nama } \\
\text { Pengujian }\end{array}$ & $\begin{array}{c}\text { Bentuk } \\
\text { Pengujian }\end{array}$ & $\begin{array}{l}\text { Hasil Yang } \\
\text { Diharapkan }\end{array}$ & $\begin{array}{c}\text { Hasil } \\
\text { Pengujian }\end{array}$ \\
\hline $\begin{array}{l}\text { Pengujian } \\
\text { login }\end{array}$ & $\begin{array}{c}\text { Mengklik } \\
\text { tombol } \\
\text { login }\end{array}$ & $\begin{array}{l}\text { Menampil- } \\
\text { kan form } \\
\text { login }\end{array}$ & Berhasil \\
\hline $\begin{array}{l}\text { Pengujian } \\
\text { submit } \\
\text { form } \\
\text { booking }\end{array}$ & $\begin{array}{c}\text { Mengisi } \\
\text { field } \\
\text { dengan } \\
\text { ketentuan } \\
\text { yang benar } \\
\text { dan } \\
\text { menekan } \\
\text { tombol } \\
\text { Save Data }\end{array}$ & $\begin{array}{c}\text { Menampil- } \\
\text { kan tabel } \\
\text { booking } \\
\text { yang baru } \\
\text { saja di- } \\
\text { submit } \\
\text { dibawah } \\
\text { form } \\
\text { booking }\end{array}$ & Berhasil \\
\hline $\begin{array}{l}\text { Pengujian } \\
\text { update } \\
\text { booking }\end{array}$ & $\begin{array}{c}\text { Menekan } \\
\text { tombol } \\
\text { update } \\
\text { pada data } \\
\text { yang akan } \\
\text { di-update }\end{array}$ & $\begin{array}{l}\text { Menampil- } \\
\text { kan data } \\
\text { yang dipilih } \\
\text { dalam form } \\
\text { booking }\end{array}$ & Berhasil \\
\hline $\begin{array}{l}\text { Pengujian } \\
\text { form } \\
\text { tambah } \\
\text { hewan }\end{array}$ & $\begin{array}{l}\text { Mengisi } \\
\text { field } \\
\text { dengan } \\
\text { ketentuan } \\
\text { yang benar }\end{array}$ & $\begin{array}{l}\text { Menampil- } \\
\text { kan tabel } \\
\text { daftar } \\
\text { hewan yang } \\
\text { sudah di- }\end{array}$ & Berhasil \\
\hline
\end{tabular}




\begin{tabular}{|c|c|c|c|c|c|c|c|}
\hline & $\begin{array}{c}\text { dan } \\
\text { menekan } \\
\text { tombol } \\
\text { Save Data }\end{array}$ & $\begin{array}{c}\text { submit } \\
\text { dibawah } \\
\text { form tambah } \\
\text { hewan }\end{array}$ & & $\begin{array}{c}\text { tombol } \\
\text { update user }\end{array}$ & $\begin{array}{l}\text { tombol } \\
\text { update } \\
\text { pada data } \\
\text { yang akan }\end{array}$ & $\begin{array}{l}\text { kan form } \\
\text { yang berisi } \\
\text { data yang } \\
\text { dipilih }\end{array}$ & \\
\hline \multirow{3}{*}{$\begin{array}{l}\text { Pengujian } \\
\text { update } \\
\text { hewan }\end{array}$} & \multirow{3}{*}{$\begin{array}{l}\text { Menekan } \\
\text { tombol } \\
\text { update } \\
\text { pada data } \\
\text { yang akan } \\
\text { di-update }\end{array}$} & \multirow{3}{*}{$\begin{array}{l}\text { Menampil- } \\
\text { kan data } \\
\text { yang dipilih } \\
\text { dalam form } \\
\text { data hewan }\end{array}$} & \multirow{3}{*}{ Berhasil } & & diupdate & & \\
\hline & & & & $\begin{array}{l}\text { Pengujian } \\
\text { tombol } \\
\text { hapus } \text { user }\end{array}$ & $\begin{array}{c}\text { Menekan } \\
\text { tombol } \\
\text { hapus }\end{array}$ & $\begin{array}{c}\text { Menghapus } \\
\text { data yang } \\
\text { dipilih }\end{array}$ & Berhasil \\
\hline & & & & $\begin{array}{l}\text { Pengujian } \\
\text { cetak PDF }\end{array}$ & Menekan & $\begin{array}{l}\text { Menampil- } \\
\text { kan laporan }\end{array}$ & \\
\hline \multirow{2}{*}{$\begin{array}{l}\text { Pengujian } \\
\text { tambah } \\
\text { gambar }\end{array}$} & \multirow{2}{*}{$\begin{array}{c}\text { Memilih } \\
\text { link tambah } \\
\text { gambar }\end{array}$} & \multirow{2}{*}{$\begin{array}{l}\text { Menampil- } \\
\text { kan tabel } \\
\text { daftar foto } \\
\text { dan form } \\
\text { unggah foto }\end{array}$} & \multirow[b]{2}{*}{ Berhasil } & $\begin{array}{l}\text { jadwal } \\
\text { booking }\end{array}$ & $\begin{array}{l}\text { tombol } \\
\text { cetak PDF }\end{array}$ & $\begin{array}{c}\text { dalam } \\
\text { bentuk PDF }\end{array}$ & Berhasıl \\
\hline & & & & $\begin{array}{l}\text { Pengujian } \\
\text { tambah } \\
\text { jadwal }\end{array}$ & $\begin{array}{c}\text { Menekan } \\
\text { tombol } \\
\text { tambah }\end{array}$ & $\begin{array}{l}\text { Menampil- } \\
\text { kan form }\end{array}$ & Berhasil \\
\hline \multirow[b]{2}{*}{$\begin{array}{l}\text { Pengujian } \\
\text { tombol add } \\
\text { to cart }\end{array}$} & \multirow[b]{2}{*}{$\begin{array}{c}\text { Menekan } \\
\text { tombol add } \\
\text { to cart pada } \\
\text { salah satu } \\
\text { produk }\end{array}$} & \multirow[b]{2}{*}{$\begin{array}{l}\text { Menampil- } \\
\text { kan isi } \\
\text { keranjang } \\
\text { belanja pada } \\
\text { sidebar }\end{array}$} & \multirow[b]{2}{*}{ Berhasil } & booking & booking & & \\
\hline & & & & $\begin{array}{c}\text { Pengujian } \\
\text { tombol } \\
\text { update }\end{array}$ & $\begin{array}{l}\text { Menekan } \\
\text { tombol } \\
\text { update } \\
\text { pada data }\end{array}$ & $\begin{array}{l}\text { Menampil- } \\
\text { kan form } \\
\text { yang berisi }\end{array}$ & Berhasil \\
\hline \multirow[b]{2}{*}{$\begin{array}{l}\text { Pengujian } \\
\text { tombol } \\
\text { pesan } \\
\text { sekarang }\end{array}$} & \multirow[b]{2}{*}{$\begin{array}{l}\text { Menekan } \\
\text { tombol } \\
\text { pesan } \\
\text { sekarang }\end{array}$} & \multirow[b]{2}{*}{$\begin{array}{l}\text { Menampil- } \\
\text { kan } \\
\text { pemberitahu } \\
\text { an pesanan } \\
\text { telah } \\
\text { diterima }\end{array}$} & \multirow[b]{2}{*}{ Berhasil } & booking & $\begin{array}{l}\text { yang akan } \\
\text { diupdate }\end{array}$ & $\begin{array}{l}\text { data yang } \\
\text { dipilih }\end{array}$ & \\
\hline & & & & $\begin{array}{l}\text { Pengujian } \\
\text { tombol } \\
\text { update data } \\
\text { jual beli }\end{array}$ & $\begin{array}{l}\text { Menekan } \\
\text { tombol } \\
\text { update } \\
\text { pada data } \\
\text { yang akan }\end{array}$ & $\begin{array}{l}\text { Menampil- } \\
\text { kan form } \\
\text { yang berisi } \\
\text { data yang }\end{array}$ & Berhasil \\
\hline \multirow[b]{2}{*}{$\begin{array}{l}\text { Pengujian } \\
\text { halaman } \\
\text { login } \\
\text { admin }\end{array}$} & \multirow[b]{2}{*}{$\begin{array}{c}\begin{array}{c}\text { Mengetik- } \\
\text { kan alamat } \\
\text { http://local }\end{array} \\
\frac{\text { host/petzon }}{\text { ecopy/inde }} \\
\frac{\text { x.php/admi }}{\text { n pada }} \\
\text { browser }\end{array}$} & \multirow[b]{2}{*}{$\begin{array}{l}\text { Menampil- } \\
\text { kan form } \\
\text { login admin }\end{array}$} & \multirow[b]{2}{*}{ Berhasil } & & diupdate & & \\
\hline & & & & $\begin{array}{c}\text { Pengujian } \\
\text { cetak PDF } \\
\text { jadwal } \\
\text { jemput, } \\
\text { jadwal } \\
\text { booking } \\
\text { dan laporan }\end{array}$ & $\begin{array}{l}\text { Menekan } \\
\text { tombol } \\
\text { cetak PDF }\end{array}$ & $\begin{array}{c}\text { Menampil- } \\
\text { kan laporan } \\
\text { dalam } \\
\text { bentuk PDF }\end{array}$ & Berhasil \\
\hline \multirow[b]{2}{*}{$\begin{array}{l}\text { Pengujian } \\
\text { tambah } \\
\text { kategori }\end{array}$} & \multirow{2}{*}{$\begin{array}{c}\text { Menekan } \\
\text { tombol } \\
\text { tambah } \\
\text { kategori }\end{array}$} & \multirow[b]{2}{*}{$\begin{array}{c}\text { Menampil- } \\
\text { kan form } \\
\text { kategori }\end{array}$} & \multirow[b]{2}{*}{ Berhasil } & penjualan & \multirow{5}{*}{$\begin{array}{l}\text { Mengirim } \\
\text { SMS } \\
\text { dengan } \\
\text { format } \\
\text { JEMPUT } \\
\text { (spasi) } \\
\text { JENIS_HE } \\
\text { WAN } \\
\text { (spasi) } \\
\text { USER_ID } \\
\text { (spasi) } \\
\text { TANGGA } \\
\text { L (spasi) } \\
\text { JAM }\end{array}$} & & \\
\hline & & & & \multirow{4}{*}{$\begin{array}{l}\text { Pengujian } \\
\text { keyword } \\
\text { JEMPUT } \\
\text { dengan } \\
\text { format } \\
\text { yang benar }\end{array}$} & & \multirow{4}{*}{$\begin{array}{l}\text { Mengirim } \\
\text { balasan } \\
\text { SMS } \\
\text { "Terima } \\
\text { kasih telah } \\
\text { mengguna- } \\
\text { kan layanan } \\
\text { jemput dari } \\
\text { kami, hewan } \\
\text { anda akan } \\
\text { kami jemput } \\
\text { jam ... } \\
\text { tanggal ... }\end{array}$} & \multirow{4}{*}{ Berhasil } \\
\hline $\begin{array}{l}\text { Pengujian } \\
\text { tombol } \\
\text { update } \\
\text { kategori }\end{array}$ & $\begin{array}{l}\text { Menekan } \\
\text { tombol } \\
\text { update pada } \\
\text { data yang } \\
\text { akan } \\
\text { diupdate }\end{array}$ & $\begin{array}{l}\text { Menampil- } \\
\text { kan form } \\
\text { yang berisi } \\
\text { data yang } \\
\text { dipilih }\end{array}$ & Berhasil & & & & \\
\hline $\begin{array}{c}\text { Pengujian } \\
\text { tambah } \\
\text { produk }\end{array}$ & $\begin{array}{c}\text { Menekan } \\
\text { tombol } \\
\text { tambah } \\
\text { produk }\end{array}$ & $\begin{array}{l}\text { Menampil- } \\
\text { kan form } \\
\text { produk }\end{array}$ & Berhasil & & & & \\
\hline \multirow[b]{2}{*}{$\begin{array}{l}\text { Pengujian } \\
\text { tombol } \\
\text { update } \\
\text { produk }\end{array}$} & \multirow[b]{2}{*}{$\begin{array}{l}\text { Menekan } \\
\text { tombol } \\
\text { update pada } \\
\text { data yang } \\
\text { akan } \\
\text { diupdate }\end{array}$} & \multirow[b]{2}{*}{$\begin{array}{l}\text { Menampil- } \\
\text { kan form } \\
\text { produk yang } \\
\text { berisi data } \\
\text { yang dipilih }\end{array}$} & \multirow[b]{2}{*}{ Berhasil } & & & & \\
\hline & & & & \multirow{3}{*}{$\begin{array}{l}\text { Pengujian } \\
\text { keyword } \\
\text { KONFIRM } \\
\text { ASI dengan } \\
\text { format } \\
\text { yang benar }\end{array}$} & \multirow{3}{*}{$\begin{array}{l}\text { Mengirim } \\
\text { SMS } \\
\text { dengan } \\
\text { format } \\
\text { KONFIRM } \\
\text { ASI (spasi) } \\
\text { OrderID }\end{array}$} & $\begin{array}{l}\text { Mengirim } \\
\text { balasan } \\
\text { "Terima } \\
\text { kasih telah } \\
\text { berbelanja }\end{array}$ & \\
\hline $\begin{array}{l}\text { Pengujian } \\
\text { tambah } \\
\text { user }\end{array}$ & $\begin{array}{c}\text { Menekan } \\
\text { tombol } \\
\text { tambah } \\
\text { user }\end{array}$ & $\begin{array}{l}\text { Menampil- } \\
\text { kan form } \\
\text { user }\end{array}$ & Berhasil & & & $\begin{array}{c}\text { di toko } \\
\text { kami, } \\
\text { pesanan } \\
\text { anda segera }\end{array}$ & Berhasil \\
\hline Pengujian & Menekan & Menampil- & Berhasil & & & kami & \\
\hline
\end{tabular}




\section{\begin{tabular}{|l|l|l|}
\hline & & proses" \\
\hline
\end{tabular}}

\section{KESIMPULAN}

1. Berdasarkan pengujian aplikasi disertai dengan ratusan sampel data dapat disimpulkan aplikasi berjalan dengan handal dan akurat telah dibuktikan dengan perbandingan secara manual dan berulang.

2. Berdasarkan pengujian yang dilakukan, server SMS Gammu dapat menampung ratusan SMS yang masuk dan sistem autoreply yang dibuat dapat memproses lebih dari satu SMS secara bersamaan.

3. Meskipun aplikasi berjalan secara baik, namun masih terdapat kendala ketika user menginputkan nomer yang salah.

4. Pada aplikasi SMS gateway masih terdapat kendala seperti gangguan provider dan pengaturan servis SMS gateway pada windows sehingga menyebabkan data tidak masuk pada server SMS gateway..

\section{SARAN}

Berdasarkan pengujian terhadap aplikasi Sistem Informasi Penjualan Dan Pemesanan Layanan Berbasis Web Dan SMS Gateway Di Petshop "Petzone" yang telah dibuat, dapat diberikan beberapa saran sebagai berikut.

1. Aplikasi Sistem Informasi Penjualan Dan Pemesanan Layanan Berbasis Web Dan SMS Gateway Di Petshop "Petzone" ini dapat dikembangkan lebih lanjut dengan menambahkan fitur SMS gateway lagi seperti melihat jadwal klinik, promo-promo layanan dan pengingat jadwal kontrol.

\section{DAFTAR PUSTAKA}

[1] Alamsjah, Firdaus. Using Six Sigma to Improve Business Media, Yogyakarta, 2008

[2] Ladjamudin, Al Bahra Bin, Analisis dan Desain Sistem Informasi, PenerbitGraha Ilmu, Yogyakarta, 2007.

[3] Madcoms. Aplikasi Program PHP dan MySql, Penerbit Andi, Yogyakarta, 2004

[4] Michal Cihar. 2011. Gammu Documentation.

[5] Yasin, Verdi, Rekayasa Perangkat Lunak Berorientasi Objek, Mitra Wacana Media, Jakarta, 2012.

[6] Daqiqil, Ibnu. Frame Work Codeigniter Sebuah Panduan Belajar dan Praktis [On Line], http://koder.web.id/buku-codeignitergratis/
[7] Fikri, Azkal. Aplikasi Short message servive (sms) gateway untuk layanan informasi Registrasi administrasi mahasiswa. Program Studi Ilmu Komputer, Universitas Pendidikan Indonesia.

[8] Kadir, Abdul. Form Zero tO A Pro Membuat aplikasi Web dengan PHP dan Database MySQL, Penerbit Andi, Yogyakarta, 2009.

[9] Kristanto, Andri, Perancangan Sistem Informasi dan Aplikasinya, Gaya

Media, Yogyakarta, 2008.

[10] Westriningsih, Belajar JavaScript menggunakan JQuery. ANDI. Yogyakarta. 2012

\section{BiodATA PENULIS}

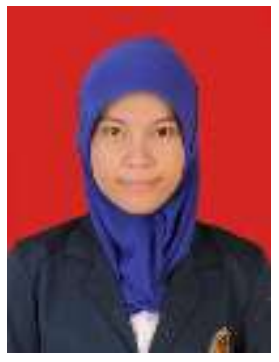

Siska Fadilah Wati, lahir di Cirebon, 25 Mei 1991.Telah menempuh pendidikan dasar di SD Purwoyoso 01 Semarang. Melanjutkan ke SMP Negeri18Semarang, dan meneruskan Pendidikan tingkat atas di SMA Negeri5Semarang, lulus tahun 2009. Dari tahun 2009 sampai saat ini tengah menyelesaikan pendidikan Strata Satu di Program Studi Teknik Sistem Komputer, Universitas Diponegoro, Semarang, Indonesia Angkatan Tahun 2009.

Menyetujui,

Dosen Pembimbing I

Adian Fatchur Rochim, S.T, M.T NIP.197302261998021001

Dosen Pembimbing II

Rinta Kridalukmana, S.Kom,MT NIP.19770615200801 